Original Article

Gopal R Sharma, MS

Department of Neurosurgery

National Academy of Medical Sciences

(NAMS)

Bir Hospital, Kathmandu, Nepal

Nilam Khadka, MCh

Department of Neurosurgery

National Academy of Medical Sciences (NAMS)

Bir Hospital, Kathmandu, Nepal

Rajiv Jha, MS, MCh

Department of Neurosurgery

National Academy of Medical Sciences (NAMS)

Bir Hospital, Kathmandu, Nepal

Dhurba R Adhikari, MS

Department of Neurosurgery

National Academy of Medical Sciences

(NAMS)

Bir Hospital, Kathmandu, Nepal

Prakash Bista, MS, MCh

Department of Neurosurgery

National Academy of Medical Sciences (NAMS)

Bir Hospital, Kathmandu, Nepal

Address for correspondence:

Gopal R Sharma, MS

Department of Neurosurgery

National Academy of Medical Sciences (NAMS)

Bir Hospital, Kathmandu, Nepal

Email: gopal47@hotmail.com

Received, May 13, 2016

Accepted, May 26, 2016

$\mathrm{P}$ revious literature on spinal tumors reveals that $55 \%$ of spinal tumors are extradurally located. ${ }^{14} 90 \%$ of extradural spinal tumors are metastases and they are usually from lung, breast, prostate and kidney. ${ }^{31} 10 \%$ of extradural spinal tumors are primary and they are neurofibromas, Ewing's sarcoma, angiolipoma, aneurysmal bone cyst. Primary extradural spinal tumors can be benign like neurofibromas, meningioma,
Nepal Journal of Neuroscience 13:3-10, 2016

\section{Extradural Spinal Tumors: Report of 36 Cases and Review of Literature}

About 55\% of spinal tumors are extradural arising from vertebral bodies, epiduraland surrounding neural and softtissues. More than $90 \%$ of extradural spinal tumors are metastaticlesions. Extradural spinal tumors are common cause of back pain, sensory motor deficit and sphincters dysfunction. The wide range of lesions and varied clinical profile, make management of spinal extradural tumors a challenging task for any neurosurgeon.

Aim of this study is to analyze and discuss the results of extradural spinal tumors after surgical treatment and relevant literature will be reviewed.

This is a retrospective study of 36 patients who were operated for spinal extradural tumors between May 1999 and December 2012 in our institute.

Follow up period ranged from 3 years to 12 years. Functional neurological outcome was assessed by McCormick's grading. There were 20 male and 16 female and age ranged from 10 to 80 years. 30 patients presented with back pain and 15 had radicular pain. On presentation 18 patients had motor sensory deficit and 15 had sphincters dysfunction. Most common involved level of spines were thoracic followed by cervical and lumbar.

Gross total excision of masses were carried out in all cases. Common pathologies were neurofibromas (16), Ewing's sarcoma (7), granulomas (3), metastatic lesions (2), angiolipoma (2), chondroma (2), aneurysmal bone cyst (1), plasmacytoma (1), rabdomyosarcoma (1) and neuroblastoma (1).

Out of 14 patients who harbored malignant pathology 12 patients received radio and chemotherapy. Post operative wound infection occurred in 5 patients. Regarding post operative neurological status, 18 patients showed improvement, 6 patients remained same and 12 patients had deteriorated neurology. Tumor recurrence occurred in 15 patients; 12 patients with malignant and 3 patients with benign lesions on follow up period. There was no surgery related mortality, however, 11 patients died during 3 years follow up period due to adverse pathology they were having.

Key Words: Extradural spinal mass, spinal tumor, surgical excision, surgical outcome 


\section{Sharma et al}

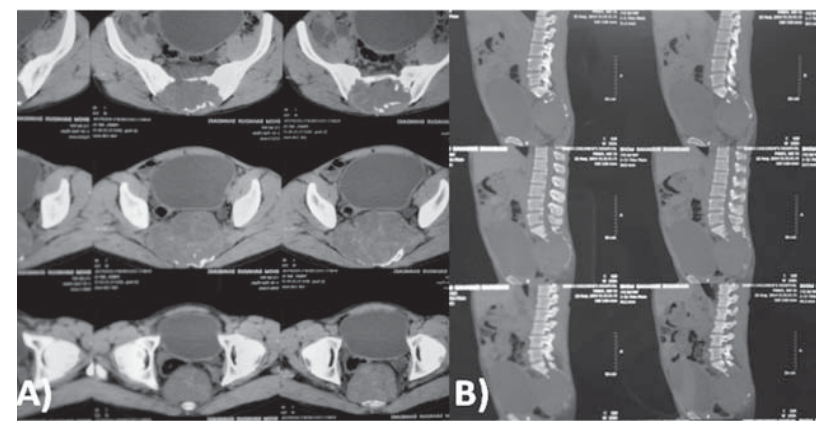

Figure 1: Preoperative CT Scan of lumbosacral spines A) axial and B) reformatted sagittal views depicted huge extradural sacral mass with erosion of surrounding bones

osteoma, giant cell tumor, vertebral hemangioma, aneurysmal bone cyst, angiolipoma etc or malignant like osteosarcoma, Ewing's sarcoma, chondrosarcoma, plasmacytoma/ multiple myeloma etc. ${ }^{3}$

These patients with extradural spinal masses usually present with back pain, radicular pain, motor and sensory deficit, sphincters dysfunction and/or combination of one of them. ${ }^{14}$ Choice of investigation is MRI with Gadolinium enhancement, isotope bone scan and search for primary lesion if there is suspicious of secondary. Treatment ranged from biopsy to total excision of tumor with or without instrumentation (depending on stability of spines) followed by radio and chemotherapy if lesions are malignant.

\section{Results}

Out of 124 cases of spinal tumors that we had operated over a period of 12 years, 36 (29.1\%) cases turned out to be extradural spinal tumors.

These 36 cases of extradural spinal tumors are the matter of discussion in this study. This is a retrospective study of 36 cases having extradural spinal tumors undergone gross total surgical excision over a period of 12 years, between May 1999 and December 2012 in our institute. There were 20 male and 16 female and age ranged from 10 to 80 years. On admission, 30 patients suffered from back pain/neck pain and 15 patients with radicular pain, 18 patients presented with sensory motor deficit and 15 patients had sphincters dysfunction. Regarding spinal level of involvement, 13 patients had thoracic, 9 had cervical, 3 had cervico thoracic, 7 had lumbar, 2 had thoracolumbar and 2 had sacral extradural masses.

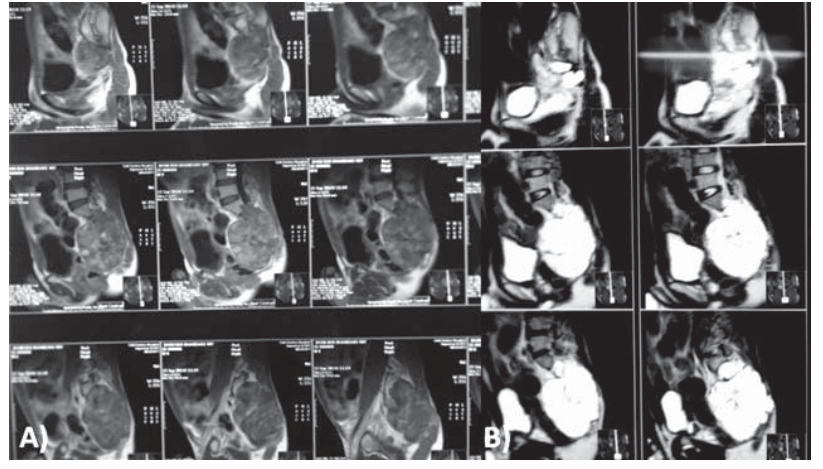

Figure 2: A) and B), Preoperative MRI of lumbosacral spines showing large extradural sacral mass suggestive of Chordoma

All patients, whether they had benign or malignant lesions, underwent gross total excision followed by instrumentation in 5 patients who had unstable spine after tumor resection (Figure1 A, B; 2 A, B and 3).

Histology revealed 2 metastatic lesions and 34 primary spinal tumors (Table 1). Among primary extradural spinal tumors 22 were benign and 12 were malignant. Primary benign lesions were neurofibromas (16), granulomas (3), angiolipoma (2) and aneurysmal bone cyst (1) (Table 1).

Primary malignant lesions were Ewing's sarcoma (7), chordoma (2), plasmacytoma (1), Rabdomyosarcoma (1) and neuroblastoma (1) (Table 2).

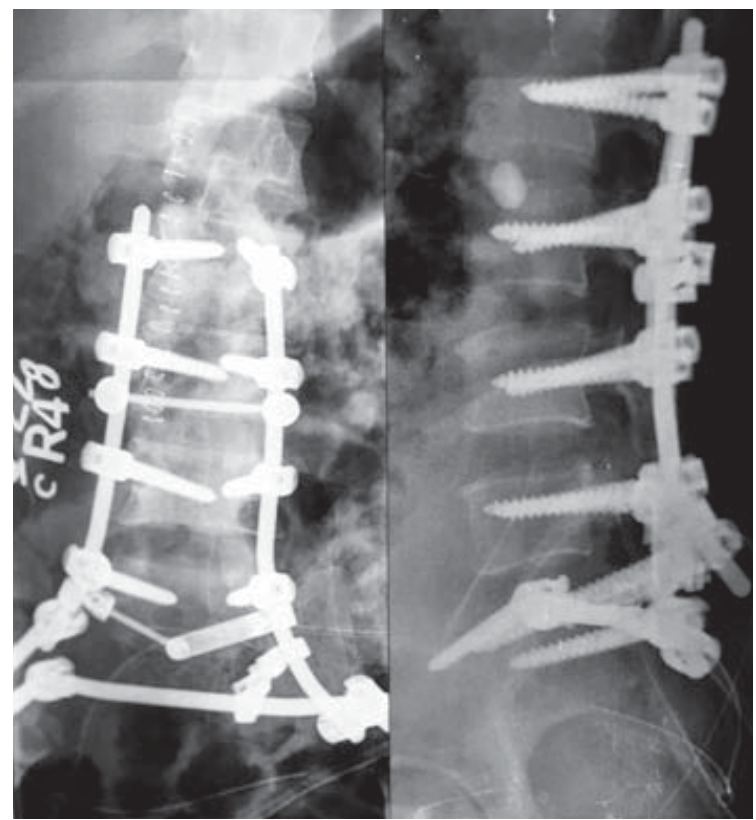

Figure 3: Postoperative plain X-Ray of lumbosacral spine after having en block excision of chordoma showed normal alignment of spine with posterior instrumentation. 
Extradural Spinal Tumor

\begin{tabular}{|l|l|l|l|}
\hline Pathology & No of cases & Extent of resection & instrumentation \\
\hline Neurofibroma & 16 & total & 2 \\
\hline Granulomas & 3 & Gross total & - \\
\hline Angiolipoma & 2 & Total & - \\
\hline Aneurysmal bone cyst & 1 & total & 1 \\
\hline
\end{tabular}

Table 1: Primary benign extradural spinal tumors

\begin{tabular}{|l|l|l|l|}
\hline Pathology & No of cases & Extent of resection & Instrumentation \\
\hline Ewing's sarcoma & 7 & Gross total & - \\
\hline Chordoma & 2 & En block & 2 \\
\hline Plasmacytoma & 1 & Total & 1 \\
\hline Rabdomyosarcoma & 1 & Gross total & 1 \\
\hline Neuroblastoma & 1 & Gross total & 1 \\
\hline
\end{tabular}

Table 2: Primary malignant extradural spinal tumors

\begin{tabular}{|l|l|l|l|}
\hline Pathology & No of cases & Extent of resection & Instrumentation \\
\hline Adenocarcinoma & 1 & Gross total & - \\
\hline Renal cell Carcinoma & 1 & Gross total & - \\
\hline
\end{tabular}

Table 3: Metastatic extradural spinal tumors

\begin{tabular}{cll} 
Preoperative neurology & \multicolumn{1}{c}{ McCormick's grade } & Postoperative neurology \\
\cline { 3 - 3 } 6 & & 15 \\
12 & I = normal neurology & 10 \\
10 & $\begin{array}{l}\text { II = mild to moderate deficit } \\
\text { III = moderate to severe deficit, } \\
\text { walks with support }\end{array}$ & 3 \\
IV = severe deficit, & wheelchair bound
\end{tabular}

Table 4: preoperative and postoperative functional outcome (McCormick grading, 1990)

Two metastatic epidural masses were adeno and renal cell carcinomas (Table 3). 10 patients who harbored primary malignant and 2 metastatic lesions were subjected for a course of radio and chemotherapy. Two patients with chordomas were not sent for radiotherapy believing that these lesions are radio resistant and in fact they both had en block resection. Post operative complication included wound infection in 5 patients, which were treated with a course of systemic antibiotics.

Despite gross total excision, 15 patients came for follow up with features of recurrence of tumors. 3 patients had recurrent neurofibromas which required second surgeries. Other 12 patients had recurrent malignant masses for which they were referred to oncology department for repeated course of radio and chemotherapy.

There was no surgery related mortality, however, we observed 11 deaths during first three years of follow up who had malignant lesions.

Functional outcome was assessed by McCormick's grading scale. Pre operatively 6 patients had grade I, 12 had grade II, 10 had grade III and 8 had grade IV. After the surgical treatment, 15 patients had grade I, 10 had grade II, 3 had grade III and 8 had grade IV (Table 4).

Nine patients' neurological status improved to grade I from grade II and III. Neurology of 7 patients improved to grade II from grade III. Neurological status of 8 patients of grade IV remained same after surgical treatment. 


\section{Sharma et al}

\section{Discussion}

Spinal tumors are a common cause of back pain, sensory motor deficit and sphincters dysfunction ..3,14 About 55\% of spinal tumors are extradural, 35\% intradural extra medullary and about $10 \%$ intramedullary.$^{31}$

More than $90 \%$ of extradural spinal tumors are metastatic and only $10 \%$ are primary extradural spinal tumors. ${ }^{31}$ Primary lesions are further divided into benign and malignant. Benign lesions are neurofibromas, meningiomas, osteomas, osteoblastmas, chondromas, osteochondromas, aneurysmal bone cysts, haemangimas, giant cell tumors, angiolipomas and granulomas. Benign tumors such as neurofibomas and meningiomas are generally intradural extramedullary but occasionally have an extradural component or may be limited to the extradural space. ${ }^{3}$ Benign extradural tumors are usually present in young adults with constant back pain, scoliosis and less often with neurological deficit.

Malignant primary extradural spinal tumors are multiple myeloma, plasmacytoma, osteosarcoma, chondrosarcoma, Ewing's sarcoma, rabdomyosarcoma and neuroblastoma. Malignant primary tumors present in middle age with back pain or spinal deformity and neurological deficits are more common.

The spinal column is the most common site of skeletal metastases in patients with cancer. ${ }^{16} \mathrm{Up}$ to $70 \%$ of cancer patients are found to have spinal metastasis on autopsy. ${ }^{28}$ Most common primary include breast, lung, prostate, kidney etc. The thoracic, lumbar and cervical spines are commonly affected. Extradural metastases are often reported. ${ }^{7}$

CT scan demonstrates well the degree of bone involvement and also helps with pre operative planning for instrumentation. MRI is preferred imaging modality. MRI demonstrates the extent of disease including paraspinal extensions and neural tissue involvement. Bone scan can detect local and distant bone pathology but has decreased specificity.

Following individual extradural spinal tumors that were commonly encountered in our study are discussed below with review of relevant literature.

\section{Primary benign extradural spinal tumors}

\section{Neurofibromas}

They are benign tumor.They are both intradural extramedullary in about $70 \%$ of cases, and remaining 30\% are equally divided between a strictly extradural location and a dumbbell ${ }^{14}$. Half of these lesions are located in thoracic spine and next half in cervical followed by lumbar spines ${ }^{3}$. Common clinical presentations are back pain with or without radiculopathy, progressive neurological deficit and bowel bladder involvement in some cases. MRI is the choice of investigation. Since they are benign lesions total surgical excision should be the aim of treatment. Prognosis has been excellent after the surgical resection, however, some recurrences have been reported in the literature.$^{3}$

\section{Angiolipoma}

Spinal angiolipomas are rare benign extradural spinal tumors. They contain mature lipomatous elements and proliferating vessels. They account for only $0.14 \%-1.2 \%$ of the spinal tumors and about 3\% of extradural spinal tumors. ${ }^{36}$ Angiolipoma is benign and noninfiltrating lesion, however, few cases of infiltrating angiolipomas have been described in literature. ${ }^{23,24,38}$ These tumors occur in young and middle age and female are mainly affected ${ }^{45}$. Most angiolipomas are located in thoracic level and arise in the posterior extradural space. 1, 11, 17, 38 Pure lumbar localization is extremely rare. ${ }^{32,36}$

The histopathogenesis of angiolipoma is unknown. They probably arise from abnormal primitive pluripotential mesenchymal cell that can differentiate into lipomatous, angiomatous or mixed tissue. ${ }^{9}$ Some authors suggested angiolipomas to be true hematomas. ${ }^{9,14,46}$ Patients with angiolipomas most commonly have long standing pain and then develop progressive neurologic symptoms secondary to spinal cord compression. Similarly to other vascular lesions female patients with those lesions may have onset or deterioration during pregnancy. ${ }^{8,15,42}$

MRI is the imaging modality of choice in detecting angiolipomas . Angiolipomas appear as hyperintense lesions on $\mathrm{T}_{1}$ weighted images ${ }^{35}$. Gadolium enhancement is due to the vascularity of these lesions. Gadolinium infusions with fat saturation sequences are useful in the study of those lesions. ${ }^{13}$

Theselesionsarebenignlesionsandtotalexcisionshould be the aim of treatment. Surgical outcome are excellent and therehasbeennorecurrencereportedinliterature. ${ }^{1,9,11,15,17,36,45}$

\section{Tuberculoma}

The spinal column is involved in less than $1 \%$ of all cases of tuberculosis. ${ }^{2}$ The typical picture of the spinal tuberculosis is of destruction of the vertebral bodies with involvement of the adjacent discs, however, in some instances cord involvement may be secondary to epidural tuberculoma. ${ }^{2}$ This epidural tuberculoma, atypical tuberculosis, may present as compression of the spinal cord or cauda equina with features ranging from paresthesia, radiculopathy, neurological deficit and loss of sphincters function. Extradural spinal tuberculomas are difficult to identify on plain radiograph. MRI has been used to diagnose epidural granulomas. ${ }^{18,22,49}$ Final diagnosis has to be made by histopathological examination. 
Laminectomy and excision of granulomas and a course of anti tuberculosis treatment after histological verification is the ideal treatment. Results are excellent in most of the cases. ${ }^{2,22,32}$

\section{Aneurysmal Bone Cyst}

They are benign, expansile, osteolytic cystic lesions that usually arise in long bones, but up to 30\% are seen in spine. ${ }^{31}$ They account for nearly $15 \%$ of primary spine tumors ${ }^{14}$. They are commonly located in posterior elements of thoracic and lumbar spine. They are commonly found in young adults with presentation of gradual progressive pain, palpable mass and possibly progressive neurological deficits. CT reveals typical expansile, lytic lesions with a so called eggshell layer of a cortical bone surrounding the lesion. On MRI, they have a heterogeneous appearance on both $T_{1}$ weighted and $T_{2}$ weighted images, with multiple fluid filled interfaces representing loculations within the lesion. Treatment is gross total excision with instrumentation, if the spine is unstable. Intra-lesional resection with or without post operative radiation is associated with higher recurrence rate. ${ }^{31}$

\section{Primary malignant extradural spinal tumors}

\section{Ewing's Sarcoma}

This is a small, round, blue cell tumor of unknown origin. Young patients aged 10 to 30 are most commonly affected. It exists in two different clinicopathological entities; osseous Ewing's Sarcoma and extra osseous Ewing's Sarcoma. ${ }^{27}$ Most common site of occurrence is thoracic followed by cervical and lumbar spines. ${ }^{43}$ The main clinical presentation is back pain, but up to $60 \%$ of patients have neurological deficit. MRI is the diagnostic imaging study of choice. ${ }^{43}$ Best treatment is aggressive surgical resection followed by radiation and chemotherapy. ${ }^{27,40}$ The local control approaches $100 \%$ and long term survival is $86 \%$.

\section{Chordomas}

These tumors arise from remnant of notochord. They are either found in clivus (40\%) or Sacrum (60\%), peak incidence is $5^{\text {th }}$ to $6^{\text {th }}$ decade of life. ${ }^{4}$ Clinical presentations are gradual onset of back pain, numbness and motor weakness and feeling of rectal fullness or incontinence. On plain X-ray, chordomas appear as destructive lesions and can have an associated soft tissue mass. CT scan shows both the osseous and soft tissue components of the tumor and is helpful in assessing neural foraminal involvement. MRI reveals enhancements of lesion and has low to intermediate signal intensity on $\mathrm{T}_{1}$ weighted images and very high signal intensity on $\mathrm{T}_{2}$ weighted images. ${ }^{10}$
When possible en block resection should be the aim of surgical treatment and if not possible, marginal excision along with pseudo capsule with postoperative radiotherapy have been advised with mixed results. ${ }^{2}$

\section{Plasmacytoma}

Plasmacytomas are B-cell lymphocyte neoplasm and they are malignant. They can affect either vertebral bodies or posterior elements. ${ }^{3}$ Plasmacytomas are very rare entity. In about $5 \%$ of patients with multiple myeloma the disease can be diagnosed in the setting of a solitary tumor (plasmacytoma) of the bone. 50\% of plasmacytomas eventually convert into multiple myelomas after some duration. ${ }^{31}$ They are commonly found in middle and old age. Clinical presentations are usually local back pain with or without radicular pain and neurological deficit. Plain X-ray and CT scan may be the choice of preliminary investigation, however, MRI would be the best option. Most commonly involved levels are thoracic and cervical spine. Complete resection should be attempted if possible, and spine should be stabilized when indicated. Radiotherapy can be used as adjuvant treatment after surgical resection. Pathological fracture can be seen in some cases of plasmacytoma for which vertebroplasty and kyphoplasty have been tried. ${ }^{10}$ Median survival period of patients harboring a solitary plasmacytoma exceeds 60 months.

\section{Neuroblastomas}

They are rare and primarily a tumor of infancy and childhood and very rare in adult population. It originates from migrating neural crest cells destined for the adrenal medulla and sympathetic nervous system, thus, primary epidural spinal neuroblastoma is very rare and only few cases have been reported in the literature. ${ }^{19}$ The presentations are back pain, radicular pain, and neurological deficit and may be associated with sphincters dysfunction. MRI with Gadolinium enhancement is the choice of investigation. Primary lesions in the other part of the body should be searched before confirming it as a primary lesion. Histology will make the final diagnosis along with immunohistochemistry. Patients with neurological deficit require prompt surgical excision followed by radio and chemotherapy. ${ }^{19,39}$ Despite combined therapies neuroblastoma has still a poor prognosis for survival.

\section{Rabdomyosarcoma}

Primary spinal epidural rabdomyosarcoma is an extremely rare tumor and only few cases have been reported. ${ }^{20,44}$ It is a highly aggressive and rapidly growing neoplasm of skeletal muscle origin that occasionally appears in the vertebral column and spinal epidural 


\section{Sharma et al}

space. This is a disease of children and young adults. Clinically rabdomyosarcoma of spine can present with local and or radicular pain, limb weakness and bladder or bowel involvement. Radiologically primary spinal rabdomyosarcoma is usually hypointense on $\mathrm{T}_{1}$ weighted and hyperintense in $\mathrm{T}_{2}$ weighted images and shows homogeneous or inhomogeneous enhancement on contrast. 44 This malignant tumor invades local structures and metastases to remote site by lymphatic and hematogenous spread. Treatment of spinal rabdomyosarcoma requires multi-disciplinary approaches that include surgery, chemotherapy and radiotherapy. Despite aggressive treatment prognosis of this diseases is poor, however, prognosis depends on age, site of origin, extent of tumor, histology and presence or absence of metastases. ${ }^{41,48}$

\section{Metastatic extradural spinal tumors}

About 1.3 million new cases are diagnosed annually in USA with about two third of these patients developing metastatic lesions. ${ }^{31}$ The most frequently involved organs are lung, liver and bone. ${ }^{47}$ The spine is the most common site for skeletal metastasis. ${ }^{16,28}$ The most common primary site for spinal metastasis includes breast, lung, prostate and kidney. ${ }^{6}$ The studies have shown that the majority of spinal metastasis involve lumbar followed by thoracic and cervical spines, however, thoracic metastatic lesion become more symptomatic earlier than cervical and lumbar.More than $95 \%$ of spinal metastatic lesions are extradural, 5\% intradural extramedullary and less than $0.5 \%$ intramedullary, rarely encountered. ${ }^{7,29}$

Their usual clinical presentations are neck pain or back pain, radicular pain, neurological deficit and may have bowel bladder symptoms. A cancer patient with new onset of neck or back pain has spinal metastasis until proven otherwise. MRI has revolutionized the diagnosis of spinal extradural metastatic lesions which require complete examination ( $\mathrm{T}_{1}, \mathrm{~T}_{2}$ and $\mathrm{T} 1$ weighted image with gadolinium enhancement). ${ }^{34}$

Treatment of symptomatic spinal metastasis is undertaken to relieve pain and to preserve or restore neurological function. Palliation is the reasonable objective in the vast majority of cases. Surgery for spinal extradural metastatic lesion must provide both decompression of the neural elements as well as stabilization of the spinal column if required. If not medically contraindicated, steroids are recommended for any patient with neurological deficits suspected or confirmed to have extradural spinal metastasis. ${ }^{25}$

Radiotherapy has been the primary therapy for managing metastatic spinal extradural mass, however, surgical decompression followed by spinal instrumentation for stabilization has also proven effective. ${ }^{21}$
Although among primary benign extradural spinal tumors osteoma, osteoblastoma, osteochondroma, giant cell tumors,vertebral haemangiomas, aneurysmal bone cyst, neurofibroma, meningioma have been described as primary benign spinal tumors ${ }^{31}$, however , in our series neurofibromas, granulomas, angiolipomas were common benign lesions. Angiolipomas are very rare and only few cases have been reported in literature. ${ }^{1,9,11,15}$ Surprisingly, there were two angiolipomas in our series.

In our series, Ewing's Sarcoma was most common primary malignant extradural spinal pathology followed by chordoma, plasmacytoma, rabdomyosarcoma and neuroblastoma, where as in literature, osteosarcoma, Ewing's Sarcoma, chondrosarcoma, plasmacytoma, multiple myeloma were described as common spinal extradural malignant pathologies. ${ }^{31}$ Our department, as being a national neurosurgical referral centre, receives many referrals of patients harboring secondaries to spines, but we operated on only two cases. These two patients were young, had single lesion with incomplete neurology and primary lesions were disappeared after treatment. According to protocol of our institute we do not operate on those patients who have multiple secondaries in spine, old age with comorbidities, medically unfit for general anaesthesia, complete loss of neurological function and if primary lesion is still active. We did gross total excision of all tumors whether they are benign, malignant, or metastatic lesions. Five patients required posterior stabilization after the excision of extradural spinal masses, they were chordomas (2), neurofibromas(2) and aneurysmal bone cyst (1). Functional outcome was excellent in those patients who were operated for primary benign lesions. Three patients, out of 16 patients with extradural neurofibroma, presented with features of recurrence in their 5 years' followed up and required second surgery. There was no evidence of recurrence in patients with angiolipomas, granulomas and aneurysmal bone cyst till to date. Three patients with extradural spinal granulomas received 18 months' course of anti-tuberculosis drugs.

Functional outcome was not satisfactory in patients with malignant pathology and their neurology remained static despite total resection of lesions. There has been no evidence of recurrence in patients with chordomas. All the patients with Ewing's Sarcoma, rabdomysarcoma, and neuroblastoma despite gross total resection followed by radio and chemotherapy, died within 3 years' followed up due to local recurrence and distant metastases. Two patients having metastasis to spine also died within 20 months of diagnosis and treatment. 


\section{Conclusion}

Total excision should be the aim of all extradural spinal tumors whether they are benign or malignant. Benign extradural spinal tumors show excellent result after total surgical excision. Malignant lesions, whether primary or secondary, have poor prognosis despite all modalities of treatment.

\section{References}

1. Akhaddar A, Gazzaz M, Derraz S, et al. Spinal epidural angiolipomas: a rare cause of the spinal cord compression. A report of 8 cases and review of the literature. Neurochirurgie 46:523-533, 2000

2. Babhulkar SS, Tayade WB, Babhulkar SK. Atypical spinal tuberculosis. The Journal of Bone and Joint Surgery. Vol 66 -B, No 2, 1984

3. Black P, Nair S, Giannakopoulos G. Spinal epidural tumors. In: Wilkins RH, Rengachary SS,eds. Principles of Neuerosurgery, $2^{\text {nd }}$ edition. Vol II. McGraw Hill Companies,New York, USA.PP 17911804, 1996

4. Brihaya J, Ector S P, Lemort M. The management of spinal epidural metastasis. Adv Tech Stand Neurosurg16:121-176, 1988

5. Bosma JJ, Pigott TJD, Pennie BH, Jafray DC. En bloc removal of the lower lumbar vertebral body for chordoma. J Neurosurg (Spine 2) 94:284-291, 2001

6. Brotchi J, Lefranc F, Djedid R, Bruneu M. Current management of intramedullary spinal cord tumors. In: Kalangu KKN, Kato Y, Dechambenoid G, eds. Essential practice of Neurosurgery, $1^{\text {st }}$ edition. Access publishing Co.Ltd, Nagoya, Japan. 980991,2009.

7. Chade Ho. Metastatic tumors of the spine and spinal cord. In: Vinken PJ, Bruyn GW ,eds. Hand book of clinical Neurology. Amsterdam: North-Hollan publishing Co. :415-33, 1979

8. Cull DJ, Erdohazi M, Symon L. Extradural haemangiolipomas in the spinal canal: two cases presenting during pregnancy. Acta Neurochir 45:187-193, 1978

9. Ehni G, Love JG. Intraspinal lipomas : report of cases; review of the literature and clinical and pathologic study. Arch Neurol Psychiatry 54:1-28, 1945

10. Fournev DR, Gokaslan ZL. Current management of sacral chordoma. Neurosurg Focus 15:1-5, 2003

11. Fourhey DR, Tong KA, Macaulay RJ, Griebel RW. Spinal angiolipoma. Can J Neuro Sci 28:82-88,

\section{Extradural Spinal Tumor}

2001

12. Fourney DR, Rhines LD, Hentschel SJ, et al. En block resection of primary sacral tumors: classification of surgical approaches and outcome. J Neurosurg: spine 3:111-122, 2005

13. Georgy BA, Hesslink JR. Evalutation of fat suppression in contrast enhanced MR of neoplastic and inflammatory spine disease. AJNR Am J Neuroradiol 15:409-417, 1994

14. Giuffre R. Spinal Lipomas. In: vinken PJ, Bruyn GW ,eds. Hand book of clinical Neurology, vol 20: part2. Tumors of the spine and spinal cord. NorthHolland: Amsterdam . PP 103-136,1976

15. Haddad FS, Abla A, Allam C K. Extradural spinal angiolipoma. Surg neurol 26:473-486, 1986

16. Harrington KD, Metastatic disease of the spine. $\mathbf{J}$ Bone Joint Surg Am 68:1110-1115, 1986

17. Hungs M, Pare LS. Spinal angiolipoma : case report and literature review. J spinal cord med 31:315318, 2008

18. Jain J, Shanmugam V. Atypical spinal tuberculosisextra osseous extradural tuberculoma: a retrospective study. International Journal of Recent Trends in Science and Technology 14 (2):332-334, 2015

19. Jost G, Frank S, Fischer N, Taub E, Mariani L. An epidural neuroblastoma causing spinal cord compression in a 67- year old woman. Rare tumors 2(2),2010

20. Khalatbari MR, Jalaeikhoo H, Hamidi M, Moharamzad Y. Primary spinal epidural rabdomyosarcoma: a case report and review of the literature. Childs Nerv Syst 28: 1977-1980, 2012

21. Klimo P jr, Thompson CJ, Kestle JR, Schmidt MH. A meta-analysis of surgery versus conventional radiotherapy for the treatment of metastatic spinal epidural disease. Neuro Oncol 7:64-76, 2005

22. Kumar S, Jain AK, Dhammi IK, Aggarwal AN. Treatment of intraspinal tuberculoma. Clin Orthop Relit Res 460:62-66, 2007

23. Leu NH, Chen CY, Shy CG, Lu CY, Wu CS, Chen DC, Gus TH. MR Imaging of an infiltrating spinal epidural angiolipoma. Am J Neuroradiol 24:10081011, 2003

24. Lin JJ, Lin F. Two entities in angiolipomas. A study of 459 cases of lipomas with review of literature on infiltrating angiolipoma. Cancer 34:720-727, 1974

25. Loblaw DA, Mitera G, Ford M, Laperriere MJ. A 2011 updated systematic review and clinical practice guideline for the management of malignant extradural spinal cord compression. Int J Radiat Oncol Biol Phys 84:312-317, 2012

26. Mallis L. Intramedullary spinal cord tumors. Clin 


\section{Sharma et al}

Neurosurg 17: 310-330,1960

27. Mukhopadhyay P, Gairola M, Sharma M, Thulkar S, Julka P, Rath G. Primary spinal epidural extra osseous Ewing's Sarcoma: Report of five cases and literature review. Australas Radiol 45:372-379, 2001

28. Mundy GR. Mechanisms of bone metastasis. Cancer 80:1546-1556, 1997

29. Murphy KC, Feld R, Evans WK. Intramedullary spinal cord metastases from small cell carcinoma of the lung. J Clin Oncol 1:99-106,1983

30. McCormick PC, Torres R, Post KD, Stein BM. Intramedullary ependymoma of the spinal cord. J Neurosurg 72:523-532, 1990

31. Nair S, Menon G, Rao RM, Abraham M, Easwer $\mathrm{H}$, Kumar K. spinal tumors.In: Kalangu KKN, Kato Y, Dechambenoit G, eds. Essential practice of Neurosurgery. Access publishing Co.Ltd, Nagoya, Japan. 958-979, 2009

32. Nanassis K, Tsitsopoulos P, Marinopoulos D, Mintelis A, Tsitsopolous P. Lumbar spinal epidural angiolipoma. Clin Neurosci 15:460-463, 2008

33. Nussbaum ES, Rockswold GL, Bergman TA, Erickson DL, Seljeskog EL. Spinal tuberculosis: a diagnostic and management challenge. J neurosurg 83: 243-247, 1985

34. Perrin RG, Wilson JMD. Metastatic tumors of the spine.In: kalangu KKN, kato Y, Dechambenoit $\mathrm{G}$, eds.Essential practice of neurosurgery. Access publishing Co.Ltd, Nagoya, Japan. 992-1014, 2009

35. Provenzale JM, Mclendon RE. Spinal angiolipomas: MR features. Am J Neuroradiol 17:713-719, 1996

36. Rocchi G, Caroli E,Frati A, Limatti M, Savlati M. Lumbar spinal angiolipomas: report of two cases and review of the literature. Spinal Cord. 42:313316, 2004

37. Rumboldt Z, Jednacak H, Talan-Hiranilovia J, Kalousek V. Spinal epidural rabdomyosarcoma. Acta Neurochir (wien) 146:195-197, 2004

38. Robin D, Hon BA, Pelz DM, Ang LC, Lee DH, Duggal N. Infiltrating spinal angiolipoma: a case report and review of the literature. $\mathbf{J}$ spinal Disord Tech.17:456-461, 2004

39. Sandberg DI, Bilsky MH, Kushner BH, Souweidane
MM, Kramer K, Laquaglia MP, Panageas KS, Cheung NK. Treatment of spinal involvement in neuroblastoma patients. Pediatc Neurosurg 39:291-298, 2003

40. Sarrdinia S, Nouri M, Alimohammadi M, Moradi H, Amirjamshidi A. Primary spinal epidural Ewing’s Sarcoma (Primitive neuroectodermal tumor): Report of a case and meta-analysis of the reported cases in the literature. Surg Neurol Int 3:55, 2012

41. Sofiene B, Asma B, Adenane B, Nidhal M, Jalel BSK, Lassaad A, Hafedh J. Primary spinal epidural rabdomyosarcoma of the upper thoracic spine. J spine 3:193

42. Tsusumi S, Nanako Y, Abe Y, Yasumoto Y, Ito M. Spinal angiolipoma in a pregnant woman presenting with acute epidural haemorrhage. J Clin Neurosci18(6):849-851, 2011

43. Tsutsumi S, Yasumoto y, Manabe A, Ogino l, Arai $\mathrm{H}$, Ito $\mathrm{M}$. Magnetic resonance imaging appearance of primary spinal extradural Ewing's Sarcoma: case report and literature review. Clin Neuroradiol 23(2):81-85, 2013

44. Tsitsopoulos PD, Tsonidis CA, Nanasis KA, Tsoleka KD, Tauridis GN .Unusual course of an epidural rabdomyosarcoma of the upper thoracic spine. Acta Neurochir (wien) 135:198-200, 1995

45. Turgot M. spinal angiolipoma: report of a case and review of the cases published since the discovery of the tumor in 1890. Br J Neurosurg 13:30-40, 1999

46. Von Hanwehr R, Apuzzo MLJ, Ahmadi J, Chandrasoma P. Thoracic Spinal angiomyolipoma: Case report and literature review. Neurosurgery 16:406-411, 1985

47. Witham TF, Khavkin YA, Gallia GL. Surgery insight: Current management of epidural spinal cord compression from metastatic spine disease. Nat clin pract Neurol 2:87-94, 2006

48. Weiss SW, Goldblum JR . Rabdomyosarcoma. In: Weiss SW,eds. Enzinger and Weiss's soft tissue tumors. Mosby, London, PP 595-627, 2008

49. Wagle VG, Magnetic reccurrence features of epidural tuberculoma of the spine. Neurosurgery 28(6):931, 1991 